\title{
natureINSIGHT BIODIVERSITY
}

1 June 2017 / Vol 546 / Issue No 7656

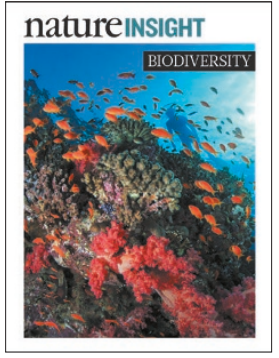

Cover image Tane Sinclair-Taylor

Editor, Nature

Philip Campbell

Publishing

Richard Hughes

Insights Editor

Ursula Weiss

Production Editor

Elizabeth Batty

Art Editor

Nik Spencer

Sponsorship

Reya Silao

Production

lan Pope

Marketing

Steven Hurst

Editorial Assistant Mary Craig

The Campus

4 Crinan Street

London N1 9XW, UK

Tel: +44 (0) 2078334000

e: nature@nature.com
$\mathrm{T}$ he tremendous diversity of life on Earth - a result of more than three billion years of evolutionary history - is facing an uncertain future. This Insight looks at how this biodiversity came to be, how it supports the goods and ecosystem services on which we depend and how it is being put to the test by the rapidly expanding human population. Crucially, strategies to safeguard this diversity are explored.

Dolph Schluter and Matthew Pennell examine how gradients in the rate of species formation over the past 20 million years have shaped, and are shaped by, some of the most pronounced biodiversity gradients on the planet.

Jonathan Levine and colleagues get to grips with the mechanisms that facilitate species coexistence in complex communities, and point to the potential importance of competitive dynamics not seen in pairwise interactions.

Forest Isbell and colleagues document the deleterious effects of human-driven biodiversity loss on ecosystem function and draw attention to the apparent intensification of these effects across temporal and spatial scales.

David Tilman and colleagues chart the increased extinction risks facing the birds and mammals of tropical Africa, Asia and South America over the next 50 years owing to rising food demand, and put forward policies to reduce these risks while bolstering food security.

The world's coral reefs support large swathes of marine life but are degrading rapidly. Terry Hughes and colleagues explore how best to safeguard these systems, calling for radical changes in coral-reef research, management and governance.

Last, Robert Pringle explores the latent conservation potential inherent in apparently failing protected areas around the world. He describes how these areas, and the benefits they bestow, can be resuscitated by embedding them in the social, cultural and economic fabric of society.

Shepherding our planet's remaining biodiversity through the current era of human population growth, environmental degradation and climatic change is one of the most pressing challenges we face. A return to past ecosystem configurations is not possible. But policies can be put in place to help avert further losses and to maintain ecosystem functions. At stake is not just the viability of the ecosystems on which we depend, but also the very richness of life, in all its colour and complexity.

\section{CONTENTS}

\section{REVIEWS}

48 Speciation gradients and the distribution of biodiversity Dolph Schluter \& Matthew W. Pennell

56 Beyond pairwise mechanisms of species coexistence in complex communities

Jonathan M. Levine, Jordi Bascompte, Peter B. Adler \& Stefano Allesina

65 Linking the influence and dependence of people on biodiversity across scales

Forest Isbell, Andrew Gonzalez, Michel Loreau, Jane Cowles, Sandra Díaz, Andy Hector, Georgina M. Mace, David A. Wardle, Mary I. O'Connor, J. Emmett Duffy, Lindsay A. Turnbull, Patrick L. Thompson \& Anne Larigauderie

73 Future threats to biodiversity and pathways to their prevention David Tilman, Michael Clark, David R. Williams, Kaitlin Kimmel, Stephen Polasky \& Craig Packer

82 Coral reefs in the Anthropocene Terry P. Hughes, Michele L. Barnes, David R. Bellwood, Joshua E. Cinner, Graeme S. Cumming, Jeremy B. C. Jackson, Joanie Kleypas, Ingrid A. van de Leemput, Janice M. Lough, Tiffany H. Morrison, Stephen R. Palumbi, Egbert H. van Nes \& Marten Scheffer

\section{PERSPECTIVE}

91 Upgrading protected areas to conserve wild biodiversity Robert M. Pringle

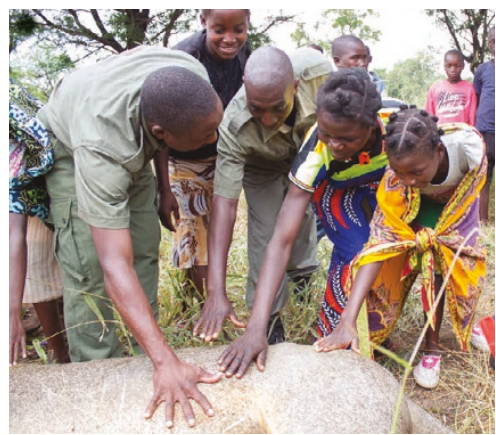

